\title{
A system for band saw wheel wear measurement
}

\author{
Tomas Sysala ${ }^{1, *}$, Karel Stuchlík ${ }^{1}$, and Petr Neumann ${ }^{2}$ \\ ${ }^{1}$ TBU in Zlin, Dept. of Automation and Control Engineering, Faculty of Appl. Informatics, Nad Stranemi 4511, Zlin, Czech Republic \\ ${ }^{2} \mathrm{TBU}$ in Zlin, Dept. of Electronics and Measurements, Faculty of Applied Informatics, Nad Stranemi 4511, Zlin, Czech Republic
}

\begin{abstract}
The article describes the design and application of a new method for the band saw parts wear grade measurement. The introduction mentiones the individual parts of a band saw in general, and it states the current method of band pass wheels wear measurement. The nowadays measurement method analysis and innovative method design follows. The article also contains the design realization and related software description. The practical measurements data samples are present together with design benefits in the Data Analysisi Section
\end{abstract}

\section{Introduction}

The measurement aims at both wheels ensuring the movement and tension of band saw blade. The wheel profile change is the wear related parameter. Those two wheels fulfil the role of band saw blade pulley. One is the driving pulley, the other serves for the blade tension adjustment. From the certain blade width, both wheels need to have the typical concave shape. That shape makes the right positioning of band blade.

The measurement provides data helping the band blade correct function. In course of sawing, the wheels are wearin down so that the band blade is not sitting in the right position any more. Providing we can measure the wheel profile as a continuous preventive inspection, it is possible to intervene in time with a servicing activity extending the band blade lifetime and improve the sawing quality.

This project is a result of cooperation with Dudr Tools Ltd. Company. That company is oriented on the saw baldes production and servicing.

\section{Bandsaws}

Bandsaws are belonging to woodworking tools. Those tools are employed for example in sawmills for tree trunk cutting in lumber like flitches, logs, planks or slabs. [1]

The universal joiner's bandsaws rank among the most extensively used bandsaws. The other very frequently used bandsaws are log bandsaw, squaring bandsaw and dimension bandsaw types.

Except for case apart, all bandsaws are in fixed or immobile verions. [1]

In comparison with other saw types, the bandsaw has thanks to thin blade the smallest cutting loss so that it produces only a few amount of sawdust. The cutting surface is smooth and high quality. The bandsaw enables also the corner cutting. Unlike the other saws, the noise level is remarkybly lower.

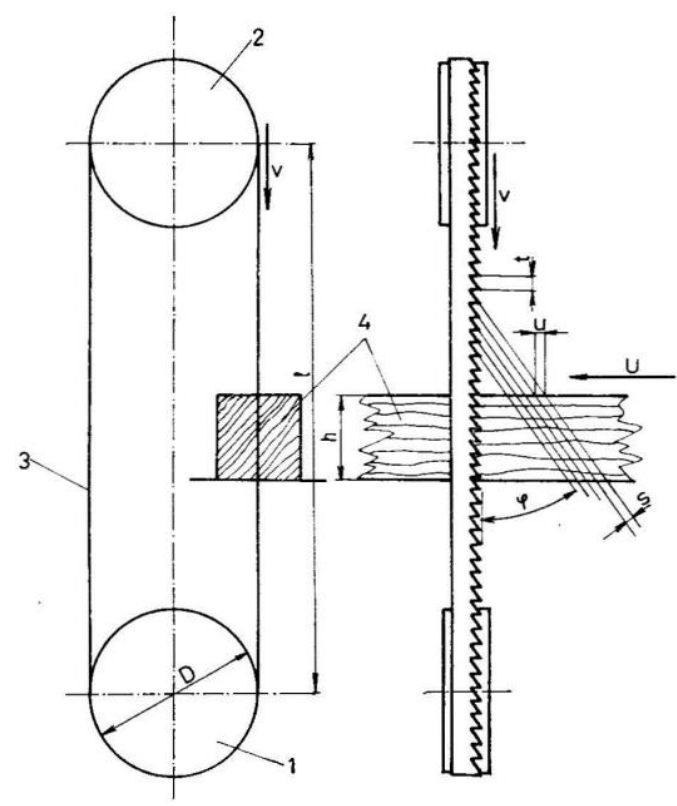

Fig. 1. The bandsaw cutting principle [1]

\subsection{The bandsaw method of operation}

The bandsaw function is based on band blade (3) that is tighten between two wheels, both the driving one (1) and the driven one (2). In an active state, the band blade runs with a constant velocity. The processed material (4) is fed either manually or mechanically.

\subsection{Band saw wheel}

The bandsaw wheels mentioned above, both the driving one and the driven one belong to bandsaw basic components. The driving wheel ensures the cutting

* Corresponding author: sysala@utb.cz 
assembly movement, and the driven wheel ensures a proper tightening and saw blade guidance.

The wheels contact area (crown) where band blade sits has a convex shape contour for saw belt width roughly above $70 \mathrm{~mm}$ for both dimension and $\log$ bandsaws. The crown exerts a pulling force, moving the blade to the top of the wheel. The band blades manufacturing, repairing and sharpening uses the rolling technology. During sawing process, the band blade bends crosswise what ensure its correct tension.

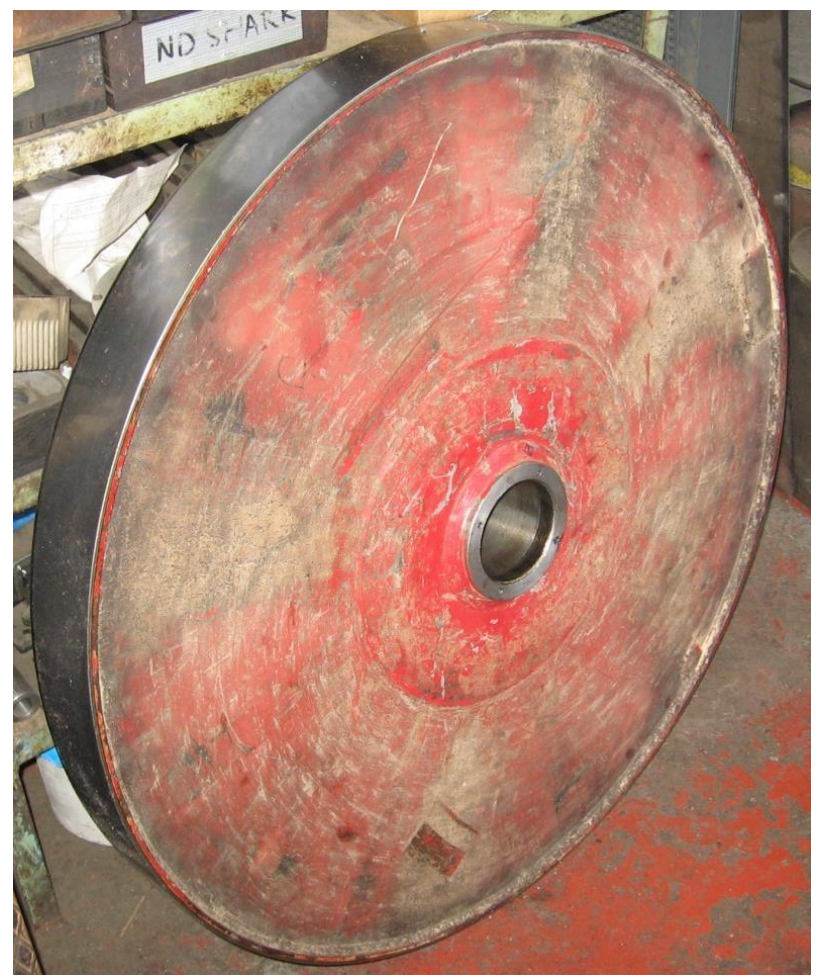

Fig. 2. The wheel prepared for servicing. [3]

The typical wheel contact area (crown) contours illustrates Figure 3.

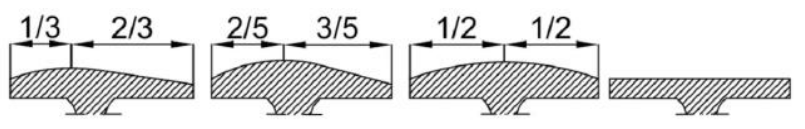

Fig. 3. Band saw wheels convex crosssection contours. [4]

The wheels wear down in course of time what causes that the saw blade doe not sit in place like expected. The wheel starts cracking, and tend not to keep the cut line during sawing. There is necessary to refurbish the blade contact area to the original shape. [4]

\subsubsection{Current wheel measurement methods}

The wear grade measurement performs with a knife-edge rule currently. That method is more an orientational checking. The rule simply puts on the wheel crown to inspect the convexity shape.

The other method consists in putting an indicator on a linear carriage. That assembly puts then on the bandsaw wheel, and the deviation measurement goes on in certain segments in relation to a reference level. We get the convex profile this way, and we can decide how to reform it with relation to the wheel rotation axis. We can use a string or a steel strip to measure the wheel circumference and calculate the corresponding correction to apply. Nevertheless, that method is quite inaccurate because of circumference measurement.

Wheel wobble measurement takes place in switchedoff mode. The indicator places on the wheel crown while wheel runs manualy. The indicator detects immediate deviation. The difference between minimal and maximal value is a wobble extent. The wheel wobble in switchedon mode and tighten saw blade is impossible to measure. The wobble of wheel in switched-on mode estimates according to the machine vibrations.

\section{INNOVATION OF MEASUREMENT}

The above described procedures imply that the current method for the wheel crown contour wear measurement is rather inaccurate. It is significantly dependent on the measuring technician skills.

There is necessary to improve the current procedure, but the basic idea is the same. One sensor reads position along the width of wheel ( $\mathrm{x}$ axis), the other sensor, mechanically coupled to the first one, indicates the assembly distance from a certain place on the wheel (y axis).

The first sensor (on the $\mathrm{x}$ axis) has to be mechanically proof and able to relocate assembly with the second sensor to a required location. At the same time, the first sensor needs to feature the smallest possible amplitude along $\mathrm{x}$ axis in course of assembly relocation. The accuracy along $\mathrm{x}$ axis is not critical. There is enough to determine the location on the wheel with an accuracy of tenth milimeters.

The second sensor (y axis) shall feature the highest possible accuracy because the wheel crow convexity variations are in the range of hundredths milimeter. The sensor errors should also be taken into account. Providing we use a contactless sensor, it has to be able to sense distance from a very shiny wheel crown surface.

\subsection{Hardware solution design}

As stated above, the acceptable measurement can be performed with two sensors.

The first idea was to programm a PLC controlling a step motor which moves the indicator along the $\mathrm{x}$ axis. The indicator values represent the distance on y-axis. Those recorded values serve for the profile curve generation. Such method would be quite demanding to design taking into account the industrial environment dirt. Programming would be also difficult.

To overcome those complications, we have changed the design concept to a linear carriage fastened to a right angle arm. The optosensor is firmly attached to the linear carriage. That sensor determines the y-coordinate on the triangulation principle. The y-coordinate is the distance of measurement assembly to the wheel. The second sensor reads the $\mathrm{x}$-coordinate what is a relative position 
with regard to the width of wheel crown. The linear incremental magnetic sensor fulfils the role of that second sensor. It is a contactless position measurement based on the magnetic field measurement of a permanent magnet. The permanent magnet in our case is a magnetic stripe attached to the rectangular arm the mechanical assembly with the magnetic sensor is moving above it. The remarkable advantage represents the mechanical resistance because of contactless measurement. Both mentioned sensors embed in a machinery manufactured by Dudr Tools Ltd.

\subsection{System concept}

The system concept supposes that all measurements processes a computer what means evaluation, printing and archiving. That is why a converter supplying power and trasfering measurement data to a computer via USB serial link interconnects sensors with computer.

The SCADA/HMI system ControlWeb is running in computer and it provides a user-friendly environment with all funcions mentioned above implemented.

\subsection{System components}

\subsubsection{Linear magnetic incremental sensors}

The magnetic sensor by Jirka and Comp. Ltd. Serves for the position measurement. That company offers sensors with good parameters for acceptable prices.

The sensor model TMLS-25B-02 with TTL output is selected for our application. Its parameters are sufficient for the assembly position evaluation, and the sensor is a cheapest one.

The magnetic sensor's signal processes a DataLab IO2/USB incremental counting module. This module communicates reliably with Control Web system. With USB interface, it is possible to establish a link with nearly any computer.

\subsubsection{Laser sensors}

Laser sensor is by the SICK Ltd. Company offering a wide range of products for automation including opto sensors.

The chosen sensor model is OD2-N50W10A0 equipped with RS-422 interface, measurement range from 40 milimeters to 60 milimeters, resolution of $5 \mu \mathrm{m}$, repeatability of $15 \mu \mathrm{m}$ and linearity of $\pm 20 \mu \mathrm{m}$. The sensor housing protects against dust and humidity penetration according to IP 67 rating. Indicative price price is 670 EUR without VAT. [7]

\subsubsection{DataLab 10}

Sensors in automation laboratories need completion with an output signal adaptor. The magnetic incremental sensor needs a suitable decoder that evaluates sensor shifting in reference to the magnetic stripe.
The DataLab IO system is a set of industrial $\mathrm{I} / \mathrm{O}$ modules cooperating with supervisory computer. Their task is either value measurement (reading) or value adjustment (writing). The join-stock company Moravské přístroje produces this module set.

The drivers for cooperation with supervisory computer in Control Web environment are also available. Moreover, the Active $\mathrm{X}$ drivers are also available what makes possible to use our system in any COM compatible development environment.

\subsubsection{DataLab IO/USB}

The DataLab IO/USB units communicate with computer via USB interface what is advantageous for some application. The useful advantages of USB interface is above all speed, versatility and easy use.

\subsubsection{Converter distribution board}

DataLab IO and other parts like either power supply modules or RS-422 converter are fixed in the distributor box to the DIN $35 \mathrm{~mm}$ bar according to the following block diagram:

The magnetic sensor TMLS-25B is connected both to the DC power suppy of 5 volts and to the inputs of the DataLab IO system incremental couter. That module communicates with computer via USB interface.

The SICK laser sensor connects to the DC power supply of 24 volts. The other pins support communication according to the RS-422 communication protocol. They connects to the terminal block of the serial convertor RS-422/USB by Papouch Ltd.

Both DataLab IO serial converter are fed from the USB bus in computer for they need only low current supply. USB interface can easily fulfil that.

Figure 5 displays the whole assembly wit the wheel. Figure 6 offers a detail view of the part with both magnetic sensor and laser sensor.

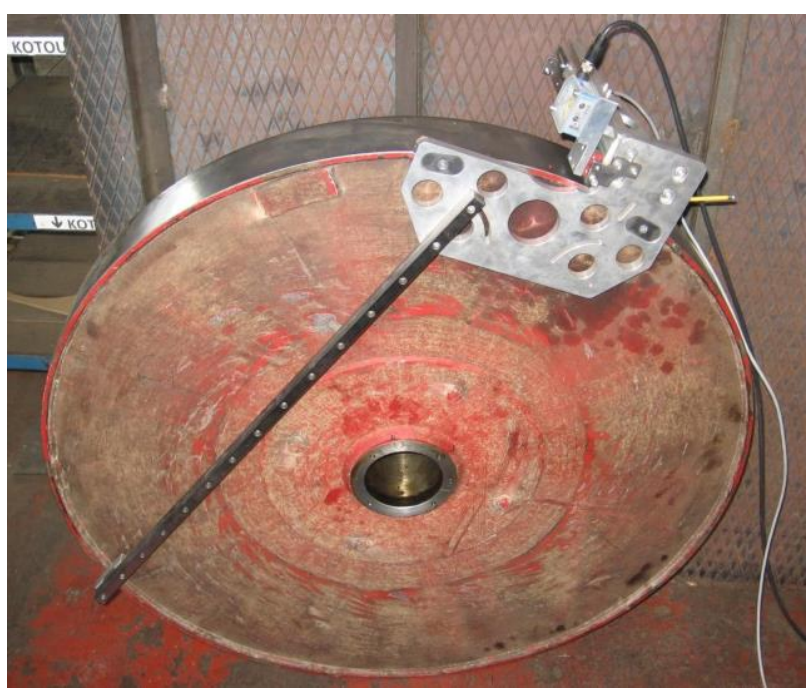

Fig. 5. Construction seated on the wheel. [3] 


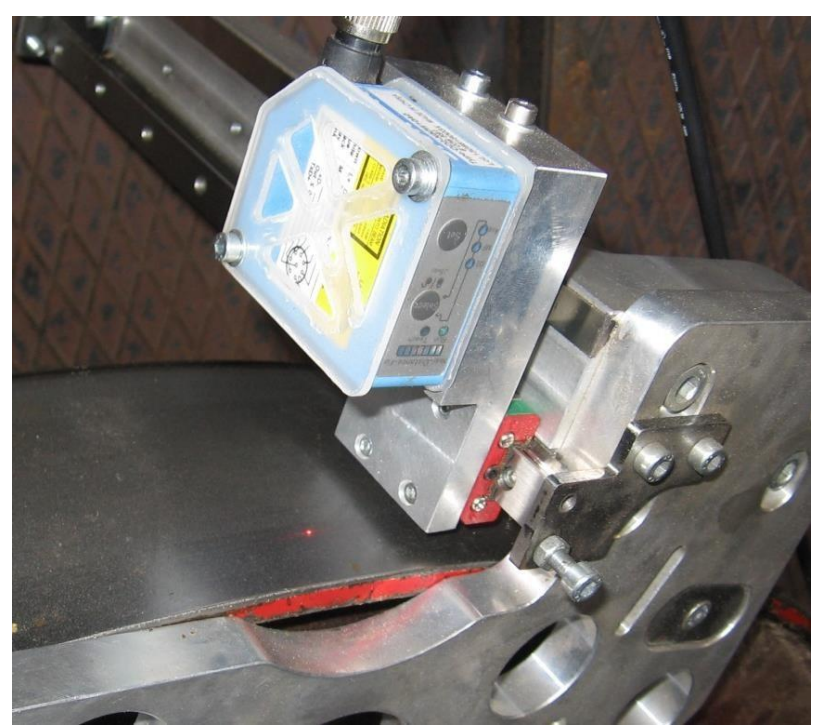

Fig. 6. Measurement assembly detail view. [3]

The assembly has permant magnets on both ends of the arm ensuring attachment to the wheel. The contact rim of wheel needs proper cleaning before measurement because the right attachment is a key condition for measurement accuracy.

\section{APPLICATION SOFTWARE}

The SCADA/HMI system Control Web creates the interface between measuring assembly and operator.

\subsection{Control Web}

Control Web is a programming tool for the development and realisation of both visual and control applications. It acts also as a tool for data collection, evaluation and storing. The DataLab IO as well as Control Web are join-stock company Moravské prrístroje products. This company founded in 1991 aims at the development and support of advanced products in the field of electronics and relevant software.

This software communicates with DataLab IO system supporting the magnetic sensor incremental pulse counter very well. This software contains also serial communication support so that any converter of that product family can communicate with the laser sensor.

\subsection{The crown countour measurement}

\subsubsection{Application description}

The application is a user-friendly easy operated environment. All measurement controlling functions are concentrated in the main window (see Figure 7) where all virtual devices are accessable.

As long as the communication with sensors runs, the indication bulb in the window upper right segment is lit on. If any communication problem happens, learn that thanks to the device above the bulb where device lists individual messages from the interface driver.

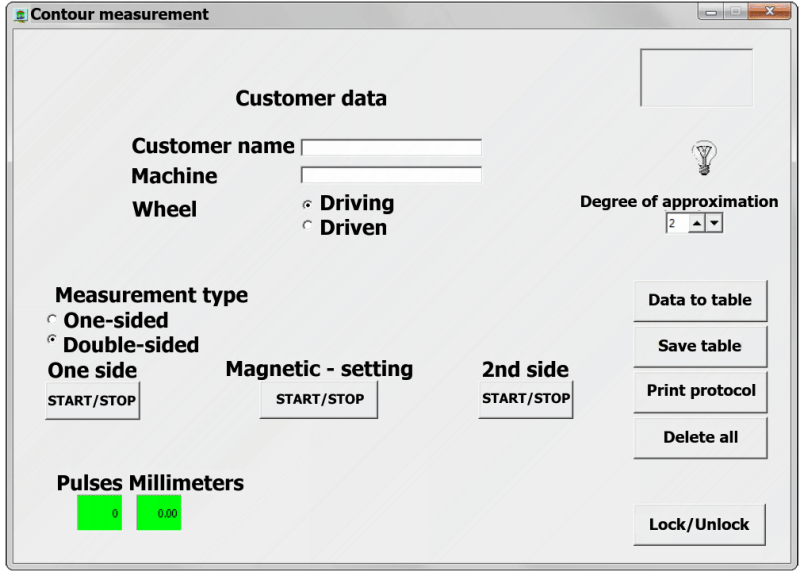

Fig. 7. Application user environment for contour measurement. [3]

The measured values can be stored in a file as both CSV format and the TBW format related to the InCalc spreadsheet.

The "PRINTOUT REPORT" button starts the printing action either on the default printer or transfer report via virtual PDF printer.to the PDF format.

\section{MEASURED DATA ANALYSIS}

\subsection{Wheel crown measurement example}

First example shows the tensioning wheel crown bifacial measurement. The measured width was roughly $93 \mathrm{~mm}$. The measurement was performed only after the wheel crown was grinded off to the required contour. The grind process was monitored with the standard method mentioned at the beginning of our article.

The ideal crown contour is symmetrical with the highest elevation in the middle of crown width. The circular crown profiles are the same specularly to the highest elevation.

The table with results in the tab "The contour chart" contains the following data: the one wheel side measurement results, the other side measurement results, measured data approximation and the curves average.

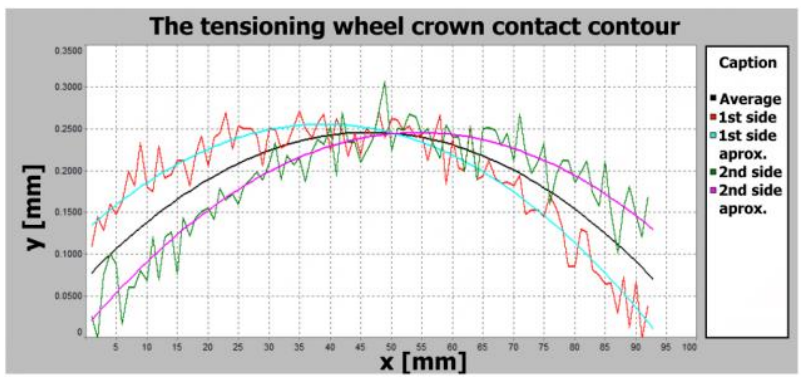

Fig. 8. The tensioning wheel crown contact contour. [3]

The other data of our interest is in the tab "Report" where the summary of all measurements is. 
Table 1. Tension wheel crown measurement results.

\begin{tabular}{|l|l|l|l|l|}
\hline $\begin{array}{l}\text { Crown } \\
\text { width }\end{array}$ & Elev. $x$ & Elev. y & $\begin{array}{l}\text { Diff. } \\
\text { in front }\end{array}$ & $\begin{array}{l}\text { Diff. } \\
\text { in back }\end{array}$ \\
\hline $93 \mathrm{~mm}$ & $46 \mathrm{~mm}$ & $0.18 \mathrm{~mm}$ & $0.17 \mathrm{~mm}$ & $0.18 \mathrm{~mm}$ \\
\hline
\end{tabular}

The measured values are very satisfying. The elevation height of $0.18 \mathrm{~mm}$ is convenient for a reliable placing and operating of band pass blade. The wheel elevation difference both in front and in back is almost the same. The small deviation is caused mainly by measurement inaccuracy.

There remains to evaluate data from the measurement accuracy point of view. The coefficient of determination is a good tool for it. That coefficient is a number from (0.1) span. It gives the accuracy of approximation. The closer that value is to 1 , the better the approximated curve corresponds with measured data. The coefficient value for the first side of the wheel is 0.91 , for the second side, it is 0.87 what is a quite acceptable result.

\subsection{Worn wheel crown measurement example}

The following example demonstrates results of a considerably worn wheel crown bifacial measurement. The crown contour should be symmetrical again.

The chart (Figure 9) and the Table 2 show the asymetricity quite clearly. The width measurement show the value of $116 \mathrm{~mm}$ what means that the contour highest elevation point is shifted a few millimeters off width centre. There is also a too big difference between height in front and in back $-0.13 \mathrm{~mm}$. The contour height of $0.34 \mathrm{~mm}$ too big because it is difficult to install saw blade in such conditions.

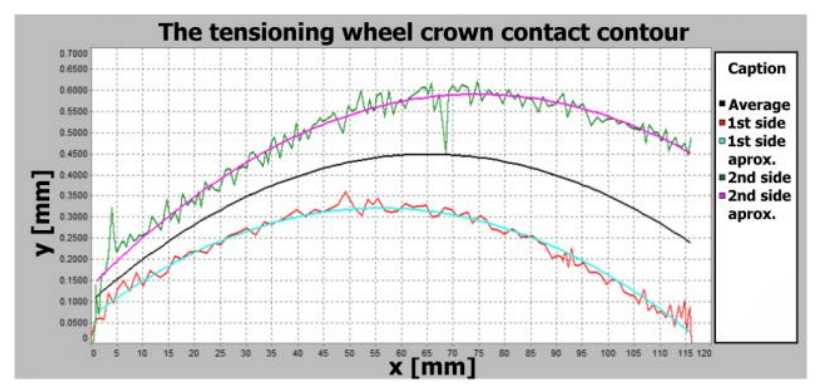

Fig. 9. The worn tensioning wheel crown contour. [3]

Table 2. Worn crown measurement results.

\begin{tabular}{|l|l|l|l|l|}
\hline $\begin{array}{l}\text { Crown } \\
\text { width }\end{array}$ & Elev. $x$ & Elev. y & $\begin{array}{l}\text { Diff. } \\
\text { in front }\end{array}$ & $\begin{array}{l}\text { Diff. } \\
\text { in back }\end{array}$ \\
\hline $116 \mathrm{~mm}$ & $65 \mathrm{~mm}$ & $0.34 \mathrm{~mm}$ & $0.34 \mathrm{~mm}$ & $0.21 \mathrm{~mm}$ \\
\hline
\end{tabular}

The determination coefficient results 0.96 for the first side and 0.95 for the second side. Such result is a very good one.

The measured data shows the necessity to reshape the crown quite much.

\section{DESIGN BENEFITS}

Among the main contributions of designed methodology belongs the fact that we have a record of every performed measurement.

We can fancy the situation when the customer has a problem with the band blade cracking. We would find a cause in the crown contour asymmetry what follows in regrinding recommendation from.

The even better approach is preventive measurement to gain reason to regrind the crown before band blade starts cracking.

A benefit represents also the possibility to perform a comparative measurement before and after regrinding to assess the regrinding efficiency.

\section{CONCLUSION}

The project result is the design of device enabling an objective evaluation of band saw wheel crown state. Thanks the measured data archiving possibility and preventive measurement, it is possible to forestall the band blade cracking and to save costs.

Another benefit is represented by the fact that the measurement can perform a wider range of workers with softer requirements on skills and experience unlike it was at older way of measurement.

In the future, efforts will be made to extend and expand the proposed and implemented system by the possibility of measuring and archiving parameters - not only for the saw-wheel, but also for other parts of the saw; and especially, the saw blade. It will be possible to count the number of teeth on/of the saw-blade, its sawlength, flatness - and other features and parameters that allow for the prolonged, trouble-free operation of the saw.

This work was supported by the Ministry of Education, Youth and Sports of the Czech Republic within the National Sustainability Programme project No. LO1303 (MSMT-7778/2014) and by the European Regional Development Fund under the project CEBIA-Tech No. CZ.1.05/2.1.00/03.0089.

\section{References}

1. L. Maňas, F. Kočara. Stroje a zařizeni pro dřevařský prümysl - Machines and equipment for the wood industry - (in czech), 1, 272, (1979)

2. Direct Industry, [Online] Available: http://www.directindustry.com/prod/pilous/product25748-1216673.html

3. K. Stuchlík, Měrení profilu pásovnice u pásových pil pro pořez kulatiny - (in czech), bachelor work, 1, (TBU in Zlin, 2015)

4. Š. Barcík, M. Kvietkova, J. Bomba, M. Siklienka, Dřevoobráběci nástroje - údržba a provozování (in czech), ISBN 978-80-87415-80-1, 1, (2013)

5. Jirka a spol, [Online] Available: http://www.jirkaspol.cz/magneticke-snimace-1.html 
6. Sick: Sensor Intelligence, [Online] Available: https://www.sick.com/cz/cs/c/PRODUCT ROOT\#g1 32151

7. Sick: Sensor Intelligence, [Online] Available: https://www.sick.com/de/en/distance-sensors/shortrange-distance-sensors-displacement/od-value/od2n50w10a0/p/p185870

8. Moravian Instruments, [Online] Available: https://www.mii.cz/cat?id=189\&lang=405 P. 